\title{
National Interest or Climate Change Issues: A Discussion with References to the International Relation Theories and European Union Countries
}

\author{
Yu Gao ${ }^{1, *}$, , Yuchen $\mathrm{Liu}^{2, \dagger}$, Wenhui $\mathrm{Yu}^{3, \dagger}$
}

\author{
${ }^{1}$ Qibao Dwight High school, Minhang, Shanghai, China \\ ${ }^{2}$ Communication University of China, Beijing, China \\ ${ }^{3}$ Adam Smith Business School, University of Glasgow, Glasgow, UK \\ *Corresponding author. Email: ygao_selina@qibaodwight.org \\ These authors contributed equally.
}

\begin{abstract}
With the dominance of neo-liberalism and realism, modern international relation theories seem to provide no possible win-win solution for collaboration in facing world climate changes issues. This article examines the traditional bargain between the national interest motivated actions with responsible actions in facing the climate changes by EU countries, taking Germany and France as examples. It is argued that both countries take the constructivism view based on their specific profit concerns, which could be an adaptable mode for other countries to study with.
\end{abstract}

Keywords: European Union countries, Liberalism, Constructivism.

\section{INTRODUCTION}

The issue of climate change is affecting how the main European economies operate. There is an overall trend towards transitioning to zero net emissions towards 2050, as part of the strategy outlined by the European Union for responding to the challenges posed by global warming [1]. The European Union has set plans to ensure that the continent's economies can function on a carbon-neutral basis by 2050 . The European Green Deal has highlighted the need to ensure that there are no emissions of greenhouse gases by the middle of the twenty-first century and that there is a "decoupling of economic growth from resource use" [2]. The objectives outlined by the European Union have to be examined in the context of how the main European nations have tackled the issue of climate change. There seems to be a push and pull between the pursuit of the national interest and the concerns need to avoid environmental degradation in how the main European countries tackle the issue of climate change. The essay's main argument is that, overall, the main European nations are trying to tie their national interests concerns to the need to solve the outstanding issues created by climate change. However, the approach undertaken varies from country to country. In the case of Germany, there seems to be a more assiduous relationship between decarbonisation and the pursuit of her national interest. This is not a situation that obtains in the case of France, where there is more reticence towards giving up the use of polluting forms of energy, such as nuclear power. Nevertheless, France and Germany operate under a Constructivist view, based on establishing a common European identity, to reconcile national interest concerns with the pursuit of an environmentalist agenda.

This essay highlights the attitudes espoused by France and Germany on matters related to climate change because they are the two largest economies of the European continent. This is why it is important to assess environmental policy at a European level through the actions undertaken by both countries. At the same time, contrasting the attitude adopted by both countries will allow us to identify the factors that determine the limits of cooperation on climate change issues at the European level [3].

Both Germany and France appear to have an attitude towards the issue of climate change that is not necessarily decoupled from national interest considerations. Both countries are aware of the need to address the concerns that emerge from global warming. This is why they are willing to endorse the policies set out by the European Union. However, it seems that the road towards decarbonisation is likely to be delayed due to the need to 
protect France and Germany's geo-economic and geostrategic interests [1].

\section{ARGUMENTS FROM LIBERALISM}

Liberalism displays its logic through sanctions or intermediary organizations such as the International Monetary Fund and the Organization for Economic Cooperation and Development [4]. Also, the Libertarian believes that the economic world is pure and perfect. There are no governments to control the economic market, which is the free market. These scholars consider that this is a better method to boom the economy. The attitude adopted by Germany is compatible with the liberal position. For Germany, as an official organization in politics and economics, the European Union is seen as a forum to advance its national interest. Therefore, the EU wants to decrease the emission of carbon since the whole European countries emit $22 \%$ carbon, and only focusing on Germany, they produced 684, 387, and 325 million metric tons of CO2 respectively in 2019. In this case, Germany has consistently been the EU's biggest emitter of carbon dioxide (CO2) emissions throughout this period [5]. Even China, the biggest producing country, did not emit such a huge carbon gas, which is incredible. Thus, Germany appears to have a less cooperative attitude on these matters, as a rapid transition towards decarbonisation is likely to harm its economy [6].

To be more specific, manufacturing is the most important business to grow the economy in Germany, and most factories pay more attention to produce high-tech products and dedicated matters, usually are really expensive and advanced due to the high-tech industries. In this complete process, all of the components are electrical machines since Germany does not believe human-made. In this circumstance, things made in Germany need to use lots of natural resources like carbon dioxide and steel. If the European Union orders Germany to abate carbon dioxide emission, it might harm the economy, and Germany's development will become slower.

Explaining with knowledge of economics, for the producer, industries generate fewer goods if they lower the amount of carbon dioxide, and producers might find the alternative pathway, which is more expensive. Thereby, the cost of production increases, and the producer is likely to be worse off. The consumer side might not have much impact like producers, but consumers have fewer choices to buy, and the price will increase, so the producers are worse off too. For the international trade, under the condition of import unchanged, the export decreases since Germany does not have many goods to supply. The amount in international trade will decrease too. Overall, the economy in Germany is worse off.
At the same time, liberalism demonstrates Germany is unwilling to obligate to limit their carbon dioxide emission as they did not want to be controlled by governments and some official organizations. Like lots of German trusts, the country can correct itself and is an agent of modernity, progress, and freedom. In addition, there is a large part of the reason for their own benefits of its own country. Therefore, there is no absolute liberalism in the world, and there is also not absolute realism. In fact, most countries have adopted a mixed policy like China which has a mixed economy, which means the government has the power to adjust, maybe in international trade, raising the tax and giving the financial support. Other stakeholders also control most of the economy. To sum up, at present, no country in the world is purely using a theory to support political power, and each theory is continuously integrated to become the most appropriate part of the country.

\section{ARGUMENTS FROM REALISM}

It is worth noting that both France and Germany can be described as "pragmatic" countries, from which one can perhaps look for the relationship between environmental protection and national interests in a realistic political concept. From a realist point of view, the international system in today's world is anarchic. In other words, in the international community, although there are international relations and international conventions, large and small, in fact, they are not binding, and any country can break them at any time - especially hegemonic countries. Under this premise, conflicts between countries are difficult to avoid [7]. Realism emphasizes two terms: power and national interest. These two terms are at the heart of any sovereign state's approach to international relations. Therefore, when using this theory to analyse a problem, countries cannot put aside their interests and talk about morality. Even the power of the state and the national interest must always come first [8]. That's to say, and there are no permanent friends, only permanent interests.

France and Germany are two countries that have had close relations since ancient times. The two countries have fought wars for hundreds of years, with countless deaths and injuries, so the relationship between France and Germany was once very poor. But after World War II, relations between the two countries gradually improved. One very big reason was that this cooperation was in the national interest of both countries at the time, and instead of choosing confrontation, it was a win-win opportunity [9]. This is also in line with the idea of realist politics: politics should serve the contemporary and should be used to explain the world as it is, not to create rules of behaviour for the future.

The time has come today, the shades of decades ago from both countries approach environmental cooperation, and their national interests can also be 
found. In recent years, Germany has been involved in many discussions on environmental protection and has been an active member of the developed capitalist countries in promoting environmental protection. But recently, Germany has also been moving forward with constructing the Nord Stream II oil pipeline to meet domestic oil demand. In this process, Germany is bound to clash with the Baltic states. Like Germany, France is now continuing to develop nuclear power to meet its energy needs. France and Germany are simultaneously cooperating on environmental protection between their countries while at the same time protecting their energy security, in some ways, even at the expense of the environment. Therefore, on this issue, both countries coincidentally put their own economic interests first. In the realist framework, the sovereign state is the sovereign actor in national affairs, so although both countries are extremely important members of the EU, it is clear that their national interests are more important than cooperation in the EU. Because in the realist view, national interests always have to come first when making decisions. There are no morals or ideals between countries, and the so-called international relations are between a group of selfish people who all mediate for their own interests.

In Germany, for example, Chancellor Angela Dorothea Merkel is a realist, which may be related to the fact that she is a scientist. She is more concerned with immediate interests than with emptiness [10]. Throughout her administration, she has reversed her position on many issues, for example, the refugee issue. Between 2015 and 2016, Merkel suddenly decided to open the borders and allow one million refugees to flood into Germany. This behaviour has led to a security crisis within Germany and an increase in crime caused by refugees. It is also because of this result that Merkel's support in the country has declined. After a few years, Merkel admitted in public that she made a mistake by taking in a large number of refugees.

Returning to the question of the relationship between environmental protection and national interests in France and Germany, in this context of pursuing the interests of the moment, cooperation on climate is only temporary, perhaps for the sake of the country's international image, perhaps for domestic votes, or perhaps really for the sake of the common future of mankind but the truth is that both countries are more inclined to prioritize their own survival, so this cooperation is fragile and temporary.

\section{THE CONSTRUCTIVISM SOLUTION}

Constructivists consider that culture is an essential factor. Cultural identity decides the allocation of interest. France and Germany are member states of the European Union; they are identified with their culture. This is a critical reason why the EU could formulate an unfiled policy in a specific field. France and Germany accept the politics drafted and implemented by the EU, but which also need assimilation or acclimatization because member states have their law, cultural, and economic situation. In December 2015, the Paris Agreement on climate change was adopted to succeed for multilateral cooperation and the EU and its member states [11]. As the host country of the Paris climate negotiations, France signed the agreement; and the German Bundestag also approved the Paris Agreement in September 2016. The priority task of the EU for the Paris Agreement is to reduce the Greenhouse Gas (GHG) emission and ensure relative transparency. The priority task of the EU for the Paris Agreement is to reduce GHG emissions and ensure relative transparency [11]. To achieve this goal, France and Germany have focused on the different emission reduction targets. In France, nuclear energy as a primary material to produce electricity will be reduced to $50 \%$ from $75 \%$ in 2025 , and the total energy consumption is dropped by $50 \%$ by 2050 [12]. It is a close relative between the issues of climate and environment and the transition of the energy system in Germany. The aim of transition is that at least $60 \%$ of renewable energy could satisfy the requirement of the national energy demand, including power, heat, and mobility. However, coal and oil as an energy source have kept a critical position in Germany; the coal extraction industry has significance in Germany due to as employer and regional identities.

Constructivists deem that the behaviour of a person, organization, or state is all constructed by social, and which do not obey an entire order or principle. France is considered the strongest comprehensive strength country among the EU, that is the common concept of the states of the EU and its identity recognition. Constructivists believe that power is constructed mainly by concept and culture. At the level of the EU, Carbon Boundary Adjustment Mechanism (CBAM) was put forward by European Commission in European Green Agreement in 2019 , in which the priority aim is avoidance the carbon leakage. For France, the proposal of the Carbon border tax is proposed by Ex-president Jacques Rene Chirac of France [13]. As the prominent supporter of a Carbon border tax and playing an essential character in the identity recognition of France by members of the EU, provide adequate support for this plan. Within the EU framework, France provides policy recommendations to lead the EU's carbon border tax implementation [13]. On a published statement in Apr. 2021, a committee of experts of France and Germany emphasized the core role of the uniform price of carbon dioxide for effective and efficient protection of the climate [14]. Meanwhile, it is necessary to utilize carbon border tax to protect the economic competitiveness under the high price of carbon dioxide [15]. This plan will bring extra revenue for the EU and help the industry backflow and achieve industrial sovereignty. However, carbon border tax enhances the entrance standard of the market for the foreign product, high energy consumption products will lose the 
competitive advantages, that may obstruct the economic development of the developing country, and it is unfavourable to protect the global climate; especially for those countries which are unable reduce the carbon emission by itself.

By the theory, the meaning of power distribution is constructed mainly by interest allocation; constructing people's inherent ideas further affects the content of interests. If we consider the activity of France and Germany within the EU as internal actuation, and if extrinsic cooperation as the external stimulus is deemed as a positive interest relation, that new idea will affect the distribution of the benefit. France and Germany all adopt pragmatic values, which is why those two countries could keep communication even cooperate with China. France supports reaching an agreement on Euro-China investment and enhances communication in culture. German Chancellor Merkel indicated that it is vital to keep communication between German, French and Chinese leaders for the economic recovery. Germany hopes to strengthen cooperation in international affairs with China and is willing to continue maintaining communication with China on issues such as climate change, biodiversity, and Africa's response to the epidemic. In 2018, Germany and France received the most capital in distributing Chinese investment in the EU [16]. France and Germany have positively performed in the governance of climate to strengthen others' cultural recognition, which is beneficial to obtain more initiative in cooperation, then allocated more interest. Interests and climates could even mutually promote when it is not contradictory; if the protection of climate severely hindered economic development, interests will be considered a priority, which is thought by pragmatic value. The strength will be reduced in climate protection.

\section{CONCLUSION}

The main members of the European Union are aware of the need to reconcile their national interests concerns with the need to address the repercussions of climate change. However, the strategy related to climate change varies from country to country. Germany is interested in ensuring that the process of decarbonisation is connected to the pursuit of its national interest. France appears to be more reticent towards relinquishing polluting forms of energy, such as nuclear power. Both France and Germany espouse a Constructivist view, based on the establishment of one common identity on environmental matters, to reconcile their national interest concerns with the attainment of a sustainable production system.

\section{REFERENCES}

[1] McMichael, A. (2019) Climate Change and the Health of Nations: Famines, Fevers, and the Fate of Populations, Oxford University Press, Oxford
[2] European Commission (2021) "A European Green Deal," https://ec.europa.eu/info/strategy/priorities2019-2024/european-green-deal_en - Accessed on June 30, 2021

[3] Delbeke, J. and Vis, P. (2019) Towards a ClimateNeutral Europe: Curbing the Trend, Routledge, London

[4] Bourdieu. P (2019) French scholar Bourdieu on the essence of neoliberalism, Nanjing university, China

[5] Carbon Dioxide emissions in Germany from 2000 to 2019, statista, Germany

[6] Mann, M. (2021) The New Climate War: The Fight to Take Back Our Planet, Public Affairs, New York

[7] Song Yang. (2021). Xi Jinping held a video summit with French and German leaders. The Central People's Government of the People's Republic of China

[8] Danfeng, Guo (2020). A study of George Kennan's political realism thought. Journal of Suzhou University of Science and Technology (Social Science Edition)

[9] Zhi Kai, Wen (2015). From arch-enemies to reconciliation between France and Germany. Science Da Guan Yuan

[10] Yinghao, Li. (2016). Merkel: Chameleon or doer. Leadership Digest

[11] Oberthür, S., \& Groen, L. (2018). Explaining goal achievement in international negotiations: the EU and the Paris Agreement on climate change. Journal of European Public Policy, 25(5)

[12] Steentjes, K., Pidgeon, N. F., Poortinga, W., Corner, A. J., Arnold, A., Böhm, G. \& Tvinnereim, E. (2017). European Perceptions of Climate Change (EPCC): Topline findings of a survey conducted in four European countries in 2016.

[13] Yu, He. (2021). France pushed hard, and the European Parliament passed the "carbon border adjustment mechanism" proposal--the carbon border tax is getting closer. https://www.imsilkroad.com/news/p/450376.html

[14] Byteclicks. (2021). Overview of Germany and EU's carbon border adjustment system and carbon trading system policy. https://byteclicks.com/19403.html

[15] Federal Ministry for Economic Affairs and Energy. Einheitlicher CO2-Preis für effektiven Klimaschutz.

[16] Hanemann, T., Huotari, M., \& Kratz, A. (2019). Chinese FDI in Europe: 2018 trends and impact of and impact of new screening policies. Merics Papers on China. Berlin: Merics and Rhodium Group. 